\title{
Effect of various additives on aluminum oxide thin films prepared by dip coating, thermal behavior, kinetics and optical properties
}

\author{
Mohammed Bouzbib ${ }^{1^{*}}$ (D) Maryam El Marouani ${ }^{2}$ and Katalin Sinkó ${ }^{3}$
}

\begin{abstract}
Aluminum oxide thin films attract research interest due to their properties. Aluminum acetate was used as an Al source with acetic acid, oxalic acid, and nitric acid as additives. The transmittance and the thickness of the films strongly depend on the additives, with the approximate bandgap energy changing from $5 \mathrm{ev}$ to $5.4 \mathrm{ev}$. The aluminum oxide film deposited by dip-coating is presented great uniform surface morphology. The knowledge of the degradation kinetics of materials is essential for investigating the thermal stability of compounds. The acetic acid thin film proved to be the most efficient additive by demonstrating interesting optoelectronic properties. The thin films deposited by dip-coating were characterized by using X-ray grazing incidence diffraction, SEM, UV-Visible spectroscopy. Gamma aluminum oxide thin films prepared by acetic acid can be a good candidate for a wide range of optical applications.
\end{abstract}

Keywords: $\mathrm{Al}_{2} \mathrm{O}_{3}$, Thin films, Dip coating, Optical properties, Additives

\section{Introduction}

Aluminum oxide thin films $\left(\mathrm{Al}_{2} \mathrm{O}_{3}\right)$ exhibits several interesting properties $[1,2]$, such as high optical transparency [3], high abrasive and corrosion resistance [4, 5], high chemical and thermal stability [6], and wide bandgap [7]. Due to the mentioned properties, aluminum oxide thin films possess a wide range of applications in optoelectronics and microelectronics devices serving as insulating [8], hard protective layers [9], surface passivation e.g. for silicon solar cells [10].

The crystalline structure of $\mathrm{Al}_{2} \mathrm{O}_{3}$ can take many different forms, including: $\alpha, \gamma, \chi, \eta, \theta, \kappa, \delta$ and $\rho$ [11].

Among these transformations, $\gamma-\mathrm{Al} 2 \mathrm{O} 3$ is a significant material that is employed in a variety of applications, including catalytic substrates in the automotive and

\footnotetext{
*Correspondence: mbouzbib@caesar.elte.hu;

mohammedbouzbib@gmail.com

'Doctoral School of Environmental Sciences, Eötvös Loránd University,

Budapest H-1117, Hungary

Full list of author information is available at the end of the article
}

petroleum sectors, composite materials for spacecraft, and abrasive and thermal wear coatings [12].

The method of deposition and the temperature of the substrate are frequent factors in the creation of these phases. At low temperatures, the amorphous phase occurs, the $\gamma$-alumina phase takes over at intermediate temperatures, and the $\mathrm{k}$ and $\alpha-\mathrm{Al} 2 \mathrm{O} 3$ phases grow at high temperatures [13].

There are various chemical and physical methods applied to prepare aluminum oxide thin films such as chemical vapor deposition (CVD) [14], atomic layer deposition (ALD) [15], Pulsed laser deposition (PLD) [16, 17], spray pyrolysis (SP) [18-20], magnetron sputtering $[16,21]$, anodization [22-24] spin coating [25], and dip coating [26-28]. Dip-coating was used due to simplicity, low cost, and the ability to produce high-quality films, and it is widely utilized for the deposition of oxide thin films [25]. 
This work aims to investigate the solvent effect on the structural, optical, and morphological properties of aluminum oxide thin film by changing different solvents. The degradation kinetics of materials is essential for investigating the thermal stability of compounds. Degradation kinetics can be studied by several methods but one of the most popular and simplest techniques widely used in the literature is the thermogravimetric analysis [29].

The morphology of the films has been investigated by grazing incidence X-ray diffraction (GIXRD), the quality of the film by scanning electron microscopy (SEM). The optical properties of aluminum oxide thin films deposited by dip-coating were characterized by UV-visible spectrophotometry. The degradation kinetics of materials was determined by thermogravimetry (TG) techniques.

\section{Materials and methods}

\section{Preparation}

The aluminum oxide thin films synthesis process is shown in (Fig.1). the starting solution was prepared by dissolving the aluminum acetate $\mathrm{Al}(\mathrm{OH})\left(\mathrm{C}_{2} \mathrm{H}_{3} \mathrm{O}_{2}\right)_{2}$ (Sigma-Aldrich, at) in $\mathrm{NaOH}$ (Molar, at) solution under an air atmosphere with $0.11 \mathrm{M}$ ratio of $\mathrm{OH}$ to $\mathrm{Al}$, the mixed solution was continuously stirred at $55^{\circ} \mathrm{C}$ for $1 \mathrm{~h}$.

To dissolve the basic aluminum acetate, various acids (nitric acid, acetic acid, and oxalic acid) were added to the basic solution to get $\mathrm{pH}=7$. The acids initialize the precipitation and stabilize the sol system [25, 26]. The acetic acid received an emphasized attention, the acetic acid plays an important role as a bidentate ligand between two $\mathrm{Al}$ ions furthering the formation of a 3D network [30].

IGEPAL CO-520 or poly (oxyethylene) nonylphenyl ether) (Sigma-Aldrich) was added as a non-ionic surfactant to the colloid solution to improve the connection between layer and substrate [31]. Thin films were deposited by a dip coating method on quartz substrate at room temperature with a constant speed $(5 \mathrm{~cm} / \mathrm{min})$ by an automated dip-coater (PTL-MM01 Dip Coater). The substrates were ultrasonically cleaned with acetone, ethanol, and deionized water dried. After coating the samples were dried at $70^{\circ} \mathrm{C}$ for $1 \mathrm{~h}$ and then heated at $600{ }^{\circ} \mathrm{C}$ for $3 \mathrm{~h}$ with a heating rate of $2^{\circ} \mathrm{C} / \mathrm{min}$ (Fig.2). the aluminum oxide thin films synthesis process is shown in (Fig.1).

\section{Kinetic approach}

There are several approaches for estimating kinetic parameters from thermogravimetric data. It is therefore essential to specify the approach adopted in any kinetic exploitation of the experimental mass loss data. In this work, the kinetic parameters are determined by the Coats Redfern method. The expression to achieve these parameters is obtained from the reaction rate. Thus, in the kinetic analysis of thermal decomposition reactions,

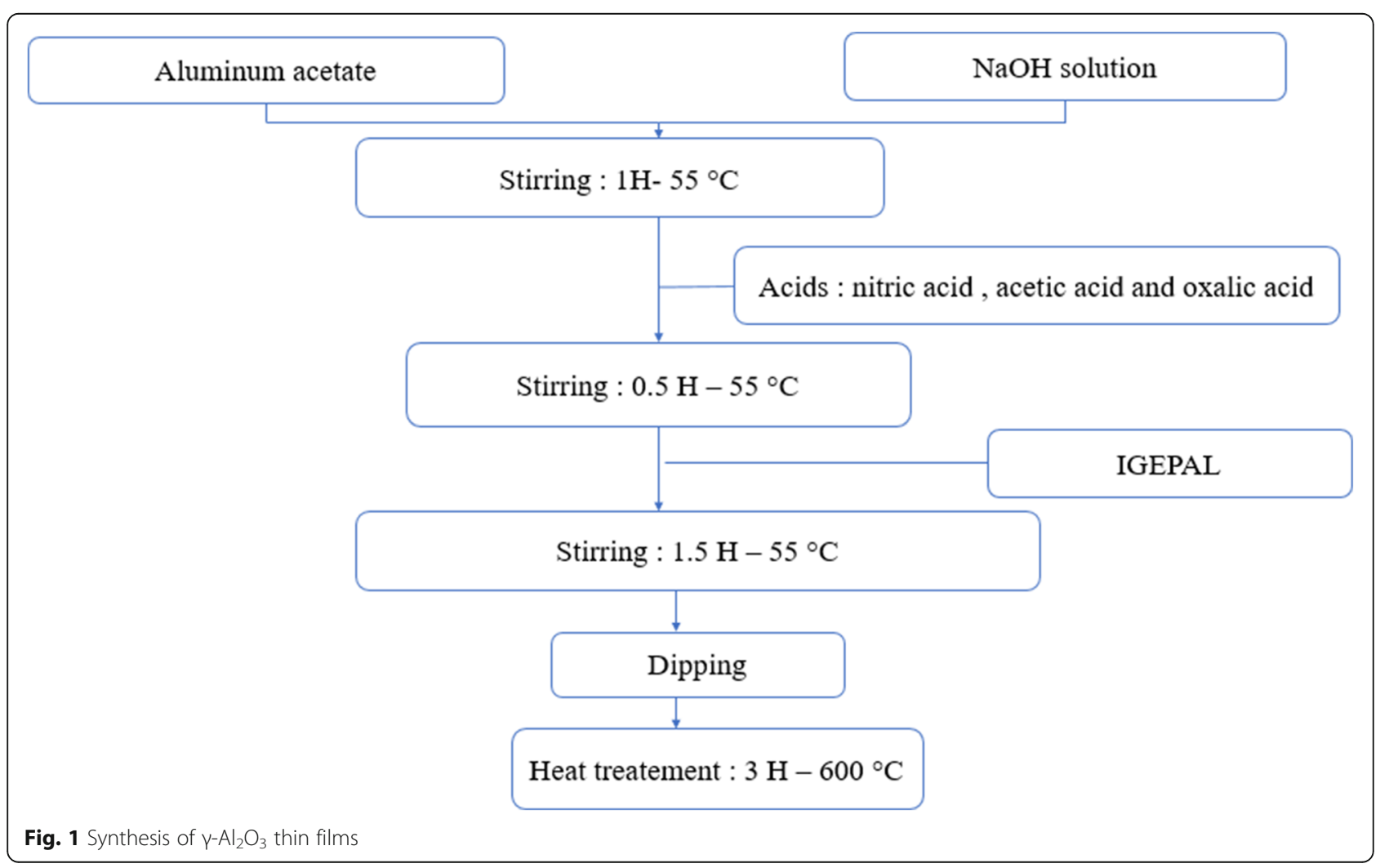




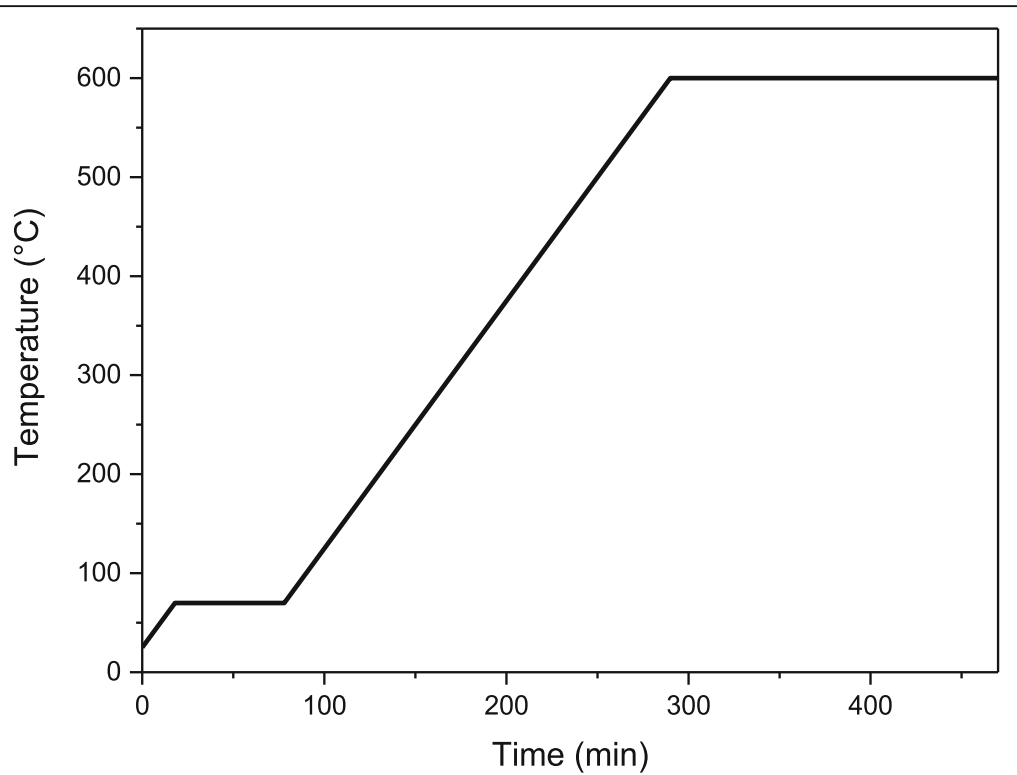

Fig. 2 Schematically graph of heat treatment of gamma aluminum oxide thin films

Table 1 Thermal degradation modes proposed for gas-solid reactions [32-34]

\begin{tabular}{|c|c|c|c|}
\hline Degradation mode & Code & Differential form: $f(a)$ & Integral form: $g(a)$ \\
\hline \multicolumn{4}{|l|}{ Diffusion } \\
\hline One-way transport & D1 & $1 /(2 a)$ & $a^{2}$ \\
\hline two-way transport, Valensi-Barrer & D2 & $-1 / \operatorname{Ln}(1-a)$ & $a+(1-a) \operatorname{Ln}(1-a)$ \\
\hline three-way transport, Jander & D3 & $1,5(1-a)^{2 / 3} /\left[1-(1-a)^{1 / 3}\right]$ & {$\left[1-(1-a)^{1 / 3}\right]^{2}$} \\
\hline Ginstling-Brounshtein & D4 & $1,5 /\left[(1-a)^{-1 / 3}-1\right]$ & $1-2 a / 3-(1-a)^{2 / 3}$ \\
\hline Zhuravlev & D5 & $1,5(1-a)^{2 / 3} /\left[1 /(1-a)^{1 / 3}-1\right]$ & {$\left[1 /(1-a)^{1 / 3}-1\right]^{2}$} \\
\hline Anti-Jander & D6 & $1,5(1+a)^{2 / 3} /\left[(1+a)^{1 / 3}-1\right]$ & {$\left[(1+a)^{1 / 3}-1\right]^{2}$} \\
\hline Kroger-Ziegler & D7 & {$\left[1,5(1-a)^{2 / 3} /\left[1-(1-a)^{1 / 3}\right]\right] / t$} & $\left.\left[1-(1-a)^{1 / 3}\right)\right]^{2}-\log (t)$ \\
\hline Two dimensions, Jander & D8 & $(1-a)^{1 / 2} /\left[1-(1-a)^{1 / 2}\right]$ & $\left.\left[1-(1-a)^{1 / 2}\right)\right]^{2}$ \\
\hline Two dimensions, Anti-Jander & D9 & $(1+a)^{1 / 2} /\left[(1+a)^{1 / 2}-1\right]$ & {$\left[(1+a)^{1 / 2}-1\right]^{2}$} \\
\hline Interfacial transfer & D10 & $3(1-a)^{4 / 3}$ & {$\left[1 /(1-a)^{1 / 3}-1\right]$} \\
\hline Transfer and diffusion & D11 & $3 /\left[(1-a)^{-4 / 3}-(1-a)^{-1}\right]$ & $1 /(1-a)^{1 / 3}-1+1 / 3 \operatorname{Ln}(1-a)$ \\
\hline Diffusion with two directions & D12 & $3 /\left[(1-a)^{-8 / 3}-(1-a)^{-7 / 3}\right]$ & $1 / 5(1-a)^{-5 / 3}-1 / 4(1-a)^{-4 / 3}+1 / 20$ \\
\hline \multicolumn{4}{|l|}{ Random nucleation and nuclei growth } \\
\hline $\begin{array}{l}\text { Avrami-Erofeev [36] } \\
n=1,2,3 \text {, } 4 \text { et } 5\end{array}$ & An & $\begin{array}{l}x(1-a)[-\operatorname{Ln}(1-a)]^{y} \\
x=4,2,3,4 / 3 \text { and } 3 / 2 \\
y=3 / 4,1 / 2,2 / 3,1 / 4 \text { and } 1 / 3\end{array}$ & $\begin{array}{l}{[-\operatorname{Ln}(1-a)]^{z}} \\
z=1 / 4,1 / 2,1 / 3,3 / 4 \text { and } 2 / 3\end{array}$ \\
\hline \multicolumn{4}{|l|}{ Chemical reactions } \\
\hline Zero order & Fo & Constant & a \\
\hline First order & F1 & $1-a$ & $-\operatorname{Ln}(1-a)$ \\
\hline Second order & F2 & $(1-a)^{2}$ & $(1-a)^{-1}-1$ \\
\hline Contraction (surface, volume and interface respectively for $n=2,3$ and 4) & Rn & $\begin{array}{l}x(1-a)^{y} \\
x=2,3 \text { et } 3 / 2 \cdot y=1 / 2,2 / 3 \text { and } 1 / 3\end{array}$ & $\begin{array}{l}1-(1-a)^{2} \\
z=1 / 2,1 / 3 \text { and } 2 / 3\end{array}$ \\
\hline \multicolumn{4}{|l|}{ Power / Exponential } \\
\hline Low power (half, third and quarter respectively for $n=2,3$ and 4 ) & Pn & $\begin{array}{l}\mathrm{na}^{\mathrm{x}} \\
\mathrm{x}=1 / 2,2 / 3 \text { and } 3 / 4\end{array}$ & $\begin{array}{l}a^{y} \\
y=1 / 2,1 / 3 \text { et } 1 / 4\end{array}$ \\
\hline Exponential & E1 & a & $\operatorname{Ln}(a)$ \\
\hline
\end{tabular}


the reaction rate is written according to the following form:

$$
\frac{d \alpha}{d t}=k f(\alpha)
$$

Where $\alpha$ is a characteristic variable of reaction progress, related to the mass of the sample $m$ by the formula:

$$
\alpha=\frac{m_{0}-m_{t}}{m_{0}-m_{f}}
$$

Where, $m_{0}$ is the initial weight of the sample, $m_{t}$ is the weight of the sample at the particular temperature $\mathrm{T}$, and $m_{\infty}$ is the weight at the end of degradation step, $f(\alpha)$ represents the mode of degradation of the substance. The function $f(\alpha)$ does not depend on the temperature but rather on the degradation mode of the subjected matter.

The different modes proposed in the literature [3234] are grouped in Table 1. In this same Table, the function $g(\alpha)=\int_{0}^{\alpha} \frac{d \alpha}{f(\alpha)}$ represents the integral form of the function $f(\alpha)$ [35].

$\mathrm{k}$ is the reaction rate constant. It is accepted that $\mathrm{k}$ following the Arrhenius law:

$$
k=A \exp \left(\frac{-E}{R T}\right)
$$

Where $\mathrm{E}$ is the apparent activation energy in $\mathrm{kJ} / \mathrm{mol}, \mathrm{R}$ is the perfect gas constant in Joules. $\mathrm{K}^{-1} \cdot \mathrm{mol}^{-1}, \mathrm{~A}$ is the pre-exponential factor or frequency factor in $\mathrm{min}^{-1}, \mathrm{~T}$ is the absolute temperature in ${ }^{\circ} \mathrm{K}$,

A, $\mathrm{E}$ and $f(\alpha)$ are called the kinetic triplets of a reaction.

$\mathbf{D}_{1}, \mathbf{D}_{2}, .$. are symbols given to models.

\section{Procedure for kinetic parameters determination}

In order to determine the kinetic parameters of our samples, the Coats-Redfern method [29], which is given in Eq.4, is expressed as follows:

$$
\operatorname{Ln}\left(\frac{g(\alpha)}{T^{2}}\right)=\operatorname{Ln} \frac{A R}{\beta E_{\alpha}}-\frac{E_{\alpha}}{R T}
$$

Where $\alpha$ is a characteristic variable of the reaction progress of the sample and $\mathrm{T}$ is the absolute temperature, $g(\alpha)$ represents functions commonly used for the description of thermal decomposition (Table 1). $A$ is the frequency factor, $E_{a}$ is the activation energy, $R$ is the gas constant, and $\beta$ is the heating rate.

A plot of $\operatorname{Ln}\left(g(\alpha) / T^{2}\right)$ against $1 / T$ will give a straight line of slope $-E / R$ and an intercept of $\ln (A R / \beta E)$ for an appropriate form of $g(\alpha)$. Thus, based on the correct form of $g(\alpha)$, the activation energy and the pre- exponential factor could be respectively determined from the slope and intercept terms of the regression line.

Table 1 lists the most common kinetic $g(\alpha)$ functions, which were used in this study for the estimation of reaction mechanisms from dynamic TG curves by using Coats-Redfern method.

\section{Investigation methods}

Scanning electron microscopy (SEM): The surface covering, and the layer thickness has been studied by a FEI Quanta 3D FEG scanning electron microscope (SEM). The SEM images were prepared by the EverhartThornley secondary electron detector (ETD), its ultimate resolution is $1-2 \mathrm{~nm}$. Since the conductance of the particles investigated is high enough to remove the electric charge accumulated on the surface, the SEM images were performed in a high vacuum without any coverage on the specimen surface. For the best SEM visibility, the particles were deposited on a HOPG (graphite) substrate surface. SEM combined with energy disperse X-ray spectroscopy (EDX) is applied for spatially resolved chemical analysis of layers.

Grazing incidence X-ray diffraction (GIXRD) measurements were performed by a Rigaku Smartlab X-ray diffractometer equipped with a $1.2 \mathrm{~kW}$ copper source (radiation wavelength: $\mathrm{CuK} \alpha ; \lambda=0.15418 \mathrm{~nm}$ ). To reduce the effect of the substrate, a grazing incidence parallel-beam geometry was used with an incidence angle of $\omega=1^{\circ}$. Scans were performed in the range $2 \Theta$ between $10^{\circ}-110^{\circ}$ with an $1 \mathrm{D}$ silicon strip detector (D/ Tex ultra 250) by a speed $0.2^{\circ} / \mathrm{min}$. The XRD data were collected over the $2 \theta$ range of $9-90^{\circ}$ with a step size $0.005^{\circ}$. Identification of phases was performed by comparing the diffraction patterns with standard PDF cards.

UV-Visible spectroscopy: The transmittance of thin films was determined by UV-visible spectroscopy using Dynamica spectrophotometer with UV Detective program at room temperature, in the range of $200-1000$ nm.

Thermogravimetric (TG) of bulk aluminum oxide were made on a simultaneous thermal analyzer of the "LabsysTMEvo (1F)" type and SETARAM brand. This device consists of a TG microbalance associated with DTA sensor with a single rod, a metal resistor furnace up to $1600^{\circ} \mathrm{C}$, and multitasking software controlling the various modules. The tests are carried out from ambient temperature to $800^{\circ} \mathrm{C}$ with a temperature rise rate of $7{ }^{\circ} \mathrm{C}$ min-1 under argon with a flow rate of $10 \mathrm{~cm}^{3}$.min1. The initial mass of the sample is about $10 \mathrm{mg}$.

\section{Results and discussion}

To determine the thermal behavior of the thin films derived from the aluminum acetate, thermogravimetry 
(TG) was used. The TG curve for AlOOH sol obtained directly by the acetic acidic treatment is shown in Fig. 3 . The small weight loss that occurred at $148^{\circ} \mathrm{C}$ is mostly caused by desorption of the adsorbed moisture and solvent evaporation, while a large weight loss happens within the temperature range from $182^{\circ} \mathrm{C}$ to $540^{\circ} \mathrm{C}$ is due to the decomposition of the organic groups by the release of $\mathrm{CO}_{2}$ and $\mathrm{H}_{2} \mathrm{O}$. No visible weight loss is detected at temperatures above $540^{\circ} \mathrm{C}$, according to the results acquired, it is suitable to calcine the aluminum oxide thin films at $600{ }^{\circ} \mathrm{C}$. When compared to bulk aluminum oxide, the aluminum oxide colloidal sol showed a significant weight loss due to solvent evaporation at $148^{\circ} \mathrm{C}$.

Figure 4 shows GIXRD patterns of the films annealed at $600{ }^{\circ} \mathrm{C}$ with various additives. The crystallinity degree can be influenced by many factors such as precursor concentration, $\mathrm{pH}$ reaction, and solvents. The films show Bragg diffraction peaks ascribed to more or less ordered $\gamma-\mathrm{Al}_{2} \mathrm{O}_{3}$ crystalline phase. The quality of acids does not really affect crystallinity. These patterns show slight shifts with different acids.

Scanning electron microscope (SEM) was used to investigate the surface morphology and cross-section of the films as shown in Fig. 5. According to SEM images, the films morphology can be described by a uniform, with no cracks and a non-defective surface. Moreover, the smooth surface morphology decreased from acetic to nitric acid and oxalic acid. The complex formed between the acetate acid and aluminum ions helps to develop a homogenous. The cross-sectional SEM images present layer thicknesses of approximately 90,140 and $115 \mathrm{~nm}$ respectively.

The chemical composition of the thin film was determined by using EDX (Fig. 6). EDX analysis from five different areas indicates the presence of $\mathrm{Al}$ and oxygenrich, beside silicon which is derived from quartz substrate of layer. The EDX confirms the efficient deposition of $\mathrm{Al}_{2} \mathrm{O}_{3}$ thin film.

To get information on the optical properties of the films, transmittance spectra of $\gamma-\mathrm{Al}_{2} \mathrm{O}_{3}$ films on quartz substrates were measured in the wavelength range from 200 to $1000 \mathrm{~nm}$ (Fig. 7). It can be noticed that the transmittance of the films is over $70 \%$ in the wavelength range from 400 to $1000 \mathrm{~nm}$. The transmittance of the films decreased from acetic, nitric, and oxalic acid respectively which confirms that thickness has an inverse relation with transmittance [37], the high absorbance of gamma aluminum oxide prepared by oxalic acid can also be explained by light trapping due to their textured morphology [38]. The optical band gap relation with the absorption coefficient is given by the relation:

$$
(\alpha \mathrm{h} v)^{2}=\mathrm{C}(\mathrm{h} v-\mathrm{Eg})
$$

Where is $\alpha$ absorption coefficient, $C$ is a constant, $h$ is Plank constant and Eg is the optical band gap. The band gap Eg can be determined by extrapolation from the

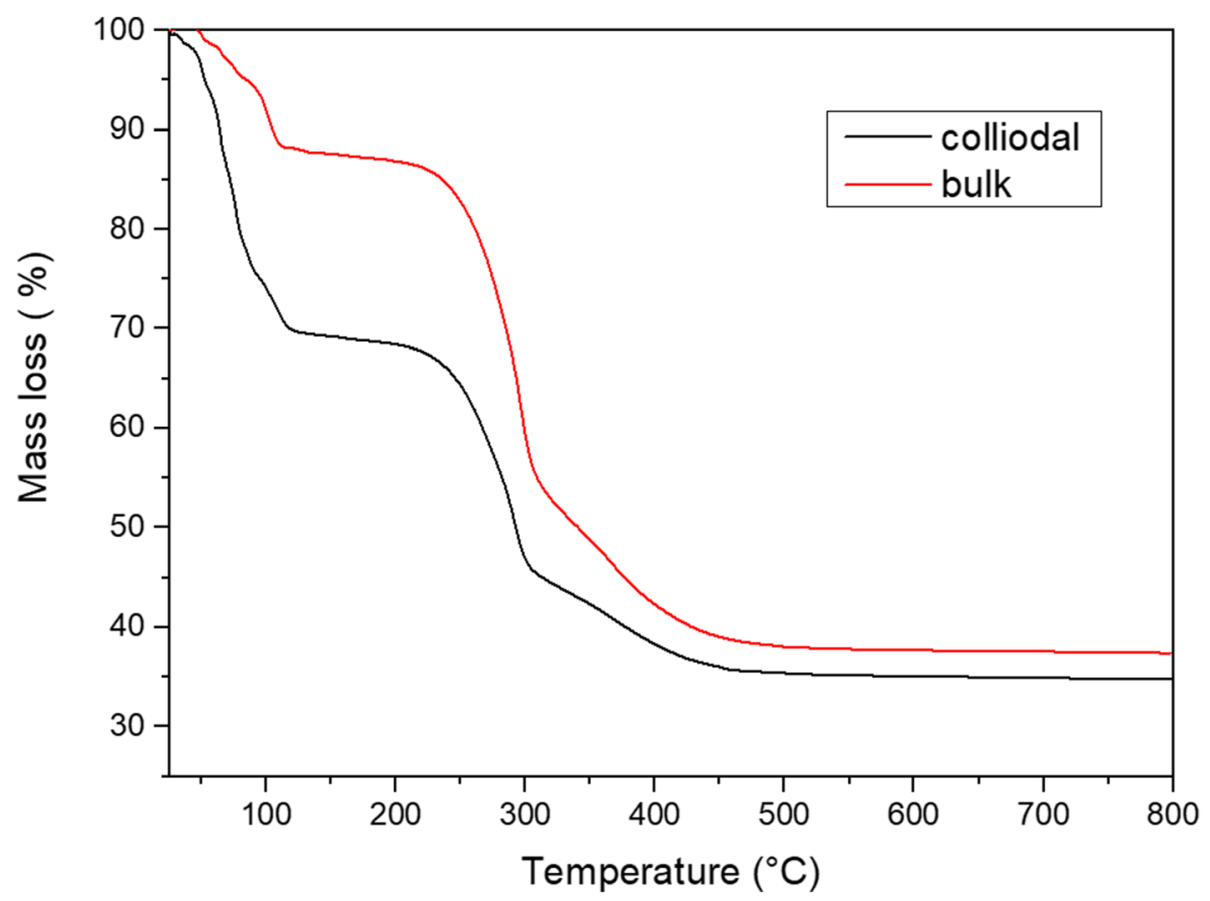

Fig. 3 Thermogravimetry (TG) of bulk aluminum oxide and colloidal sol 


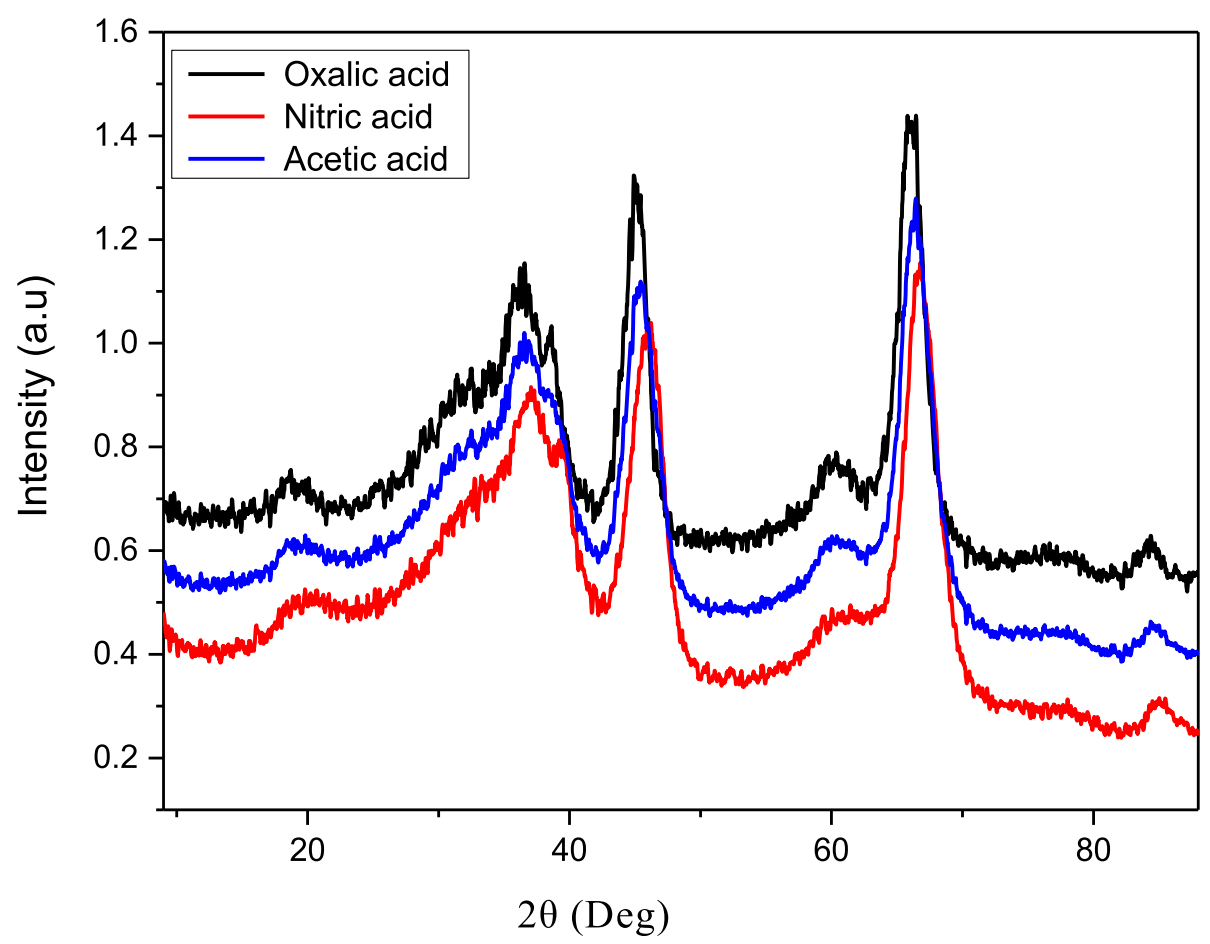

Fig. 4 Grazing incidence X-ray diffraction patterns of the films annealed at $600^{\circ} \mathrm{C}$ with various acids (nitric acid, acetic acid, and oxalic acid)

linear portion of the curves till they intercept the photon energy axis (Table 2). Figure 8. The band gap values are given as 4.99, 5.21, and $5.34 \mathrm{eV}$ for nitric acid, oxalic acid and acetic acid respectively. Band gap value can be change by some defect levels [39].

\section{Thermal analysis}

\section{Thermogravimetric analysis (TGA-DTG)}

Determination of the thermal behaviour of $\gamma-\mathrm{Al}_{2} \mathrm{O}_{3}$ thin films was carried out from the aluminum acetate, thermogravimetry (TG) was used. The TG curves for colloidal alumina sol is shown in Fig. 3. The small weight loss that occurred at $148^{\circ} \mathrm{C}$ is mostly caused by the desorption of the adsorbed moisture and solvent evaporation, While, a large weight loss happens within the temperature range from $182^{\circ} \mathrm{C}$ to $\sim 310^{\circ} \mathrm{C}$ is due to the decomposition of the organic groups (mainly acetate ions) by the release of $\mathrm{CO}_{2}$ and $\mathrm{H}_{2} \mathrm{O}$ molecules. Another escape of $\mathrm{H}_{2} \mathrm{O}$ molecules up to $540{ }^{\circ} \mathrm{C}$ can be assigned to the transformation of $\mathrm{AlOOH}$ to $\mathrm{Al}_{2} \mathrm{O}_{3}$. No detectable weight loss is above $540^{\circ} \mathrm{C}$.

\section{Kinetic parameters estimation}

To calculate and understand the nature of the decomposition, kinetic exploitation is made on a dynamic chemical regime assuming that the decomposition is a global reaction where physical limitation is neglected.
The complete thermogram was divided into distinct sections according to their degradation steps. Curves indicating the solid-state mechanisms of alumina degradation under an inert atmosphere are shown in Fig. 9. The values of activation energy Ea, preexponential factor $A$ and correlation factors $R^{2}$ for the first and second degradation steps are listed in Table 3. Moreover, the parameters $\mathrm{A}$ and $\mathrm{E}$ are moving in the same direction and their values depend on the mode of degradation. The relationship between $\mathrm{A}$ and $\mathrm{Ea}$, called the "apparent compensation effect" is often mentioned in the literature. Figure 10 shows traces of the values of $\mathrm{LnA}$ as a function of Ea. The effect of compensation is another way to further discrimination between degradation modes [40]. Thus, for the first region (second weight loss step in TGA thermogram), it was observed from Table 3 that the best correlation coefficients were obtained for F0, F1, F2, F3, R2, R3, P2, P3, D3, A2, and $\mathbf{A} 3$, with energy values running from $\mathbf{3 5 . 1}$ to $\mathbf{1 3 5 . 8}$ $\mathbf{k J} / \mathbf{m o l}$. Regarding, second degradation step (third weight loss step), degradation mechanisms that give the best mathematical fit for both samples were F1, F2, F3, R2, R3, D3 and A2, with values of activation energy from 7.154 to $121,25 \mathrm{~kJ} / \mathrm{mol}$. Likewise, results of the two regions show that the highest activation energies were found in the first thermal degradation regions where the main pyrolysis reaction took place and the 

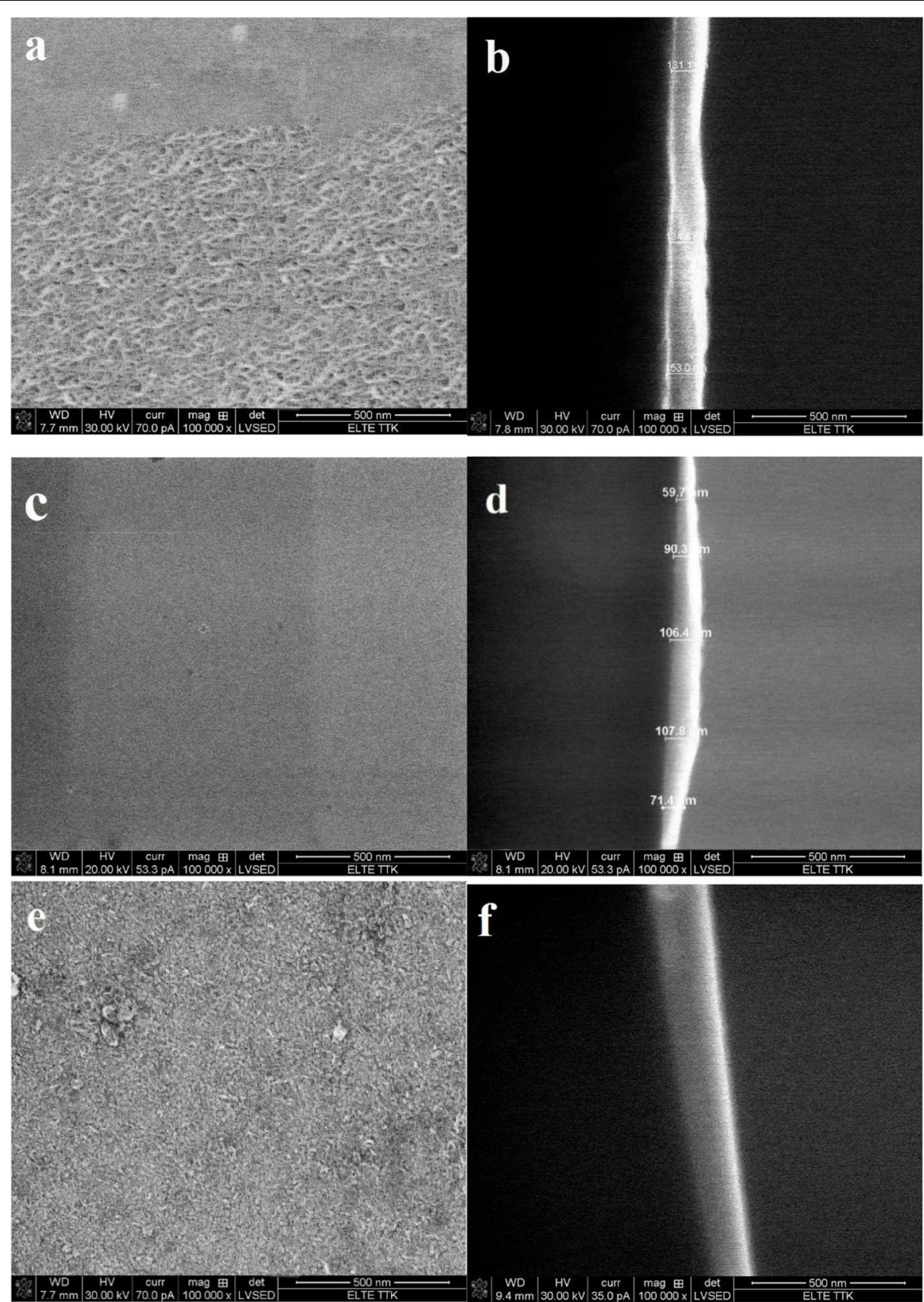

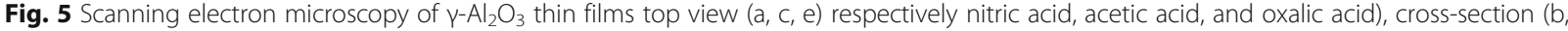
d, f)

largest weight loss occurred. The values of the preexponential factor (Table 3) indicate that it depends on the degradation mode.

\section{Conclusion}

In this work, gamma aluminum oxide thin films were prepared by various solvents. The $\mathrm{X}$-ray diffraction patterns of the films confirm the presence of $\gamma-\mathrm{Al}_{2} \mathrm{O}_{3}$ can be crystallized at a temperature of $600{ }^{\circ} \mathrm{C}$. The optical transparency of the films are over $70 \%$ in the wavelength range from 400 to $1000 \mathrm{~nm}$ with an average band gap value of $5.18 \mathrm{ev}$, therefore the $\gamma-\mathrm{Al}_{2} \mathrm{O}_{3}$ layer prepared by acetic acid shows the highest transmittance with the thinnest and smoothest surface morphology which can be relevant for many applications. The scanning electron microscopy presents a uniform no cracks and nondefective surface morphology. TGA curves indicate that active pyrolysis range is from $182^{\circ} \mathrm{C}$ to $540{ }^{\circ} \mathrm{C}$, where 


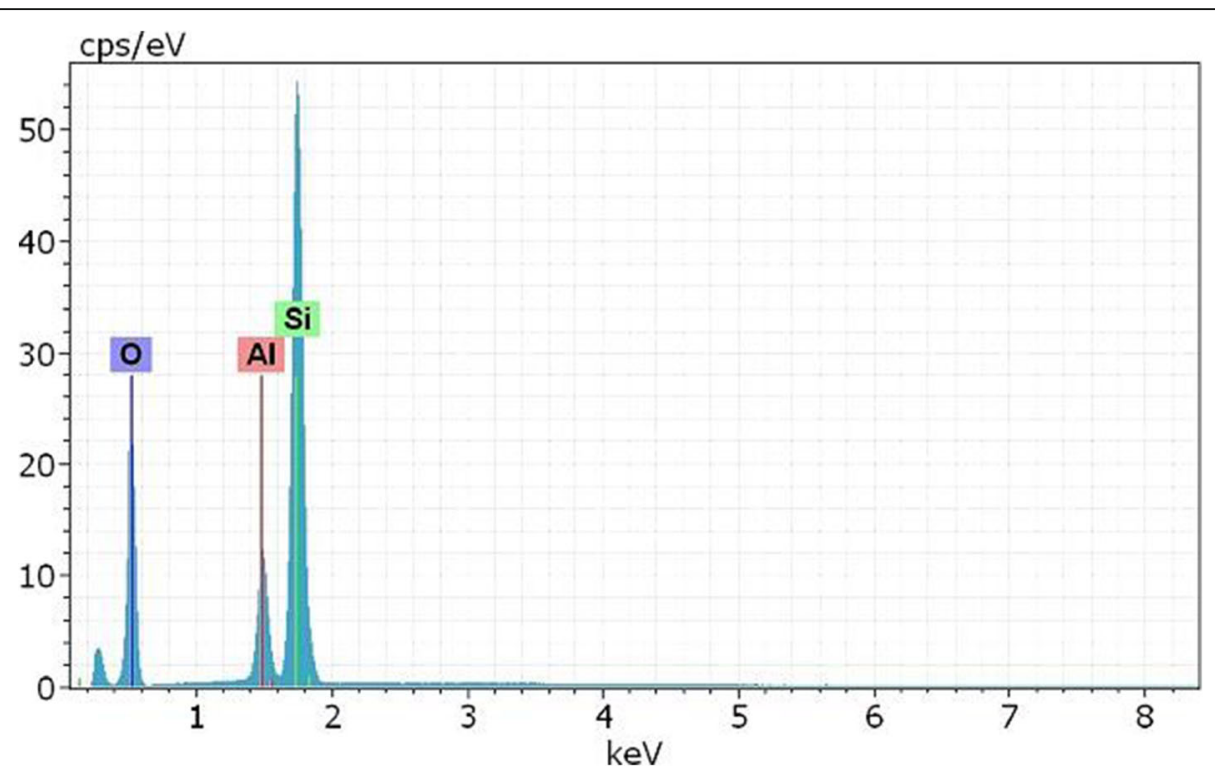

Fig. 6 EDX (Energy Dispersive $X$-ray) spectrum of $\mathrm{Al}_{2} \mathrm{O}_{3}$ thin films

the major decomposition of organic groups occur up to $\sim 310^{\circ} \mathrm{C}$ and from $\sim 310^{\circ} \mathrm{C}$ to $540{ }^{\circ} \mathrm{C} \mathrm{AlOOH}$ turns into $\mathrm{Al}_{2} \mathrm{O}_{3}$. From about $400{ }^{\circ} \mathrm{C}, \gamma$-crystalline phase begins to form. The ideal temperature of final treatment is $600{ }^{\circ} \mathrm{C}$. The results of kinetics study shows that the highest activation energies were found in the first thermal degradation region where the main pyrolysis reaction took place and the largest weight loss occurred, with values of activation energies running from 35.1 to 135.8 $\mathrm{KJ} / \mathrm{mol}$.

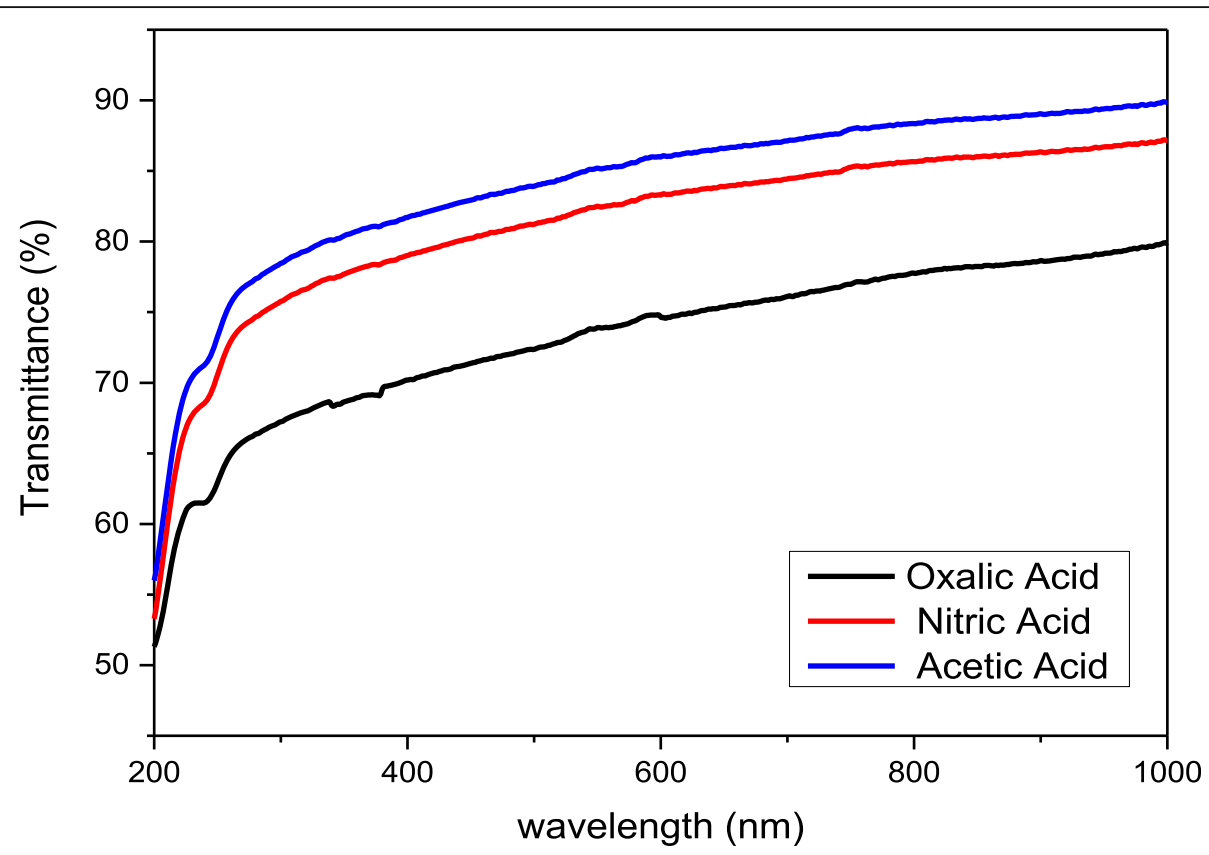

Fig. 7 Transmittance spectra of $\mathrm{y}-\mathrm{Al}_{2} \mathrm{O}_{3}$ films on quartz substrates with various acids (acetic acid, nitric acid and, oxalic acid) 
Table 2 Optical band gaps of different thin films extracted from the Tauc plot

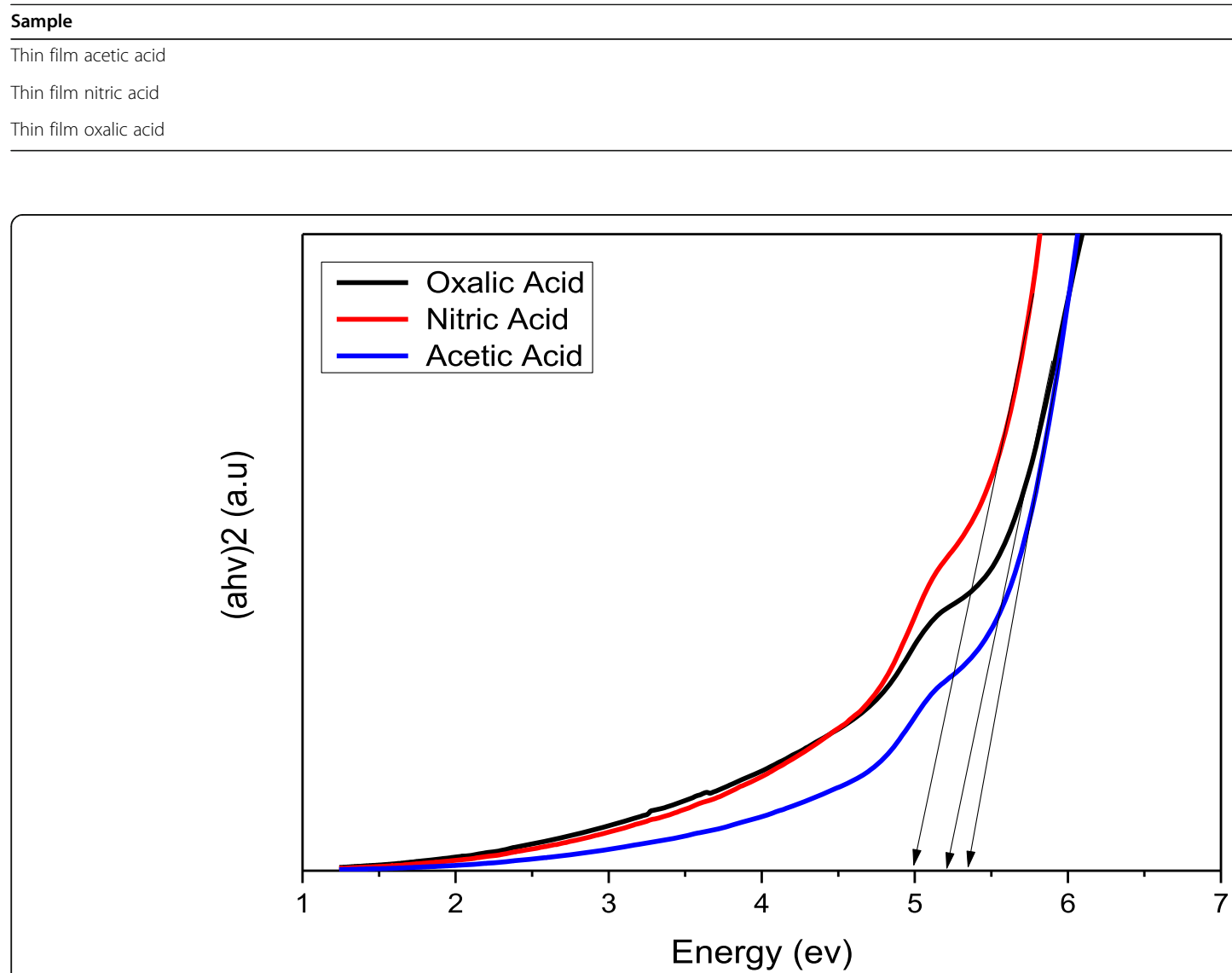

Fig. 8 The optical band gap of $\mathrm{y}-\mathrm{Al}_{2} \mathrm{O}_{3}$ films with various acids (nitric acid, acetic acid, and oxalic acid)

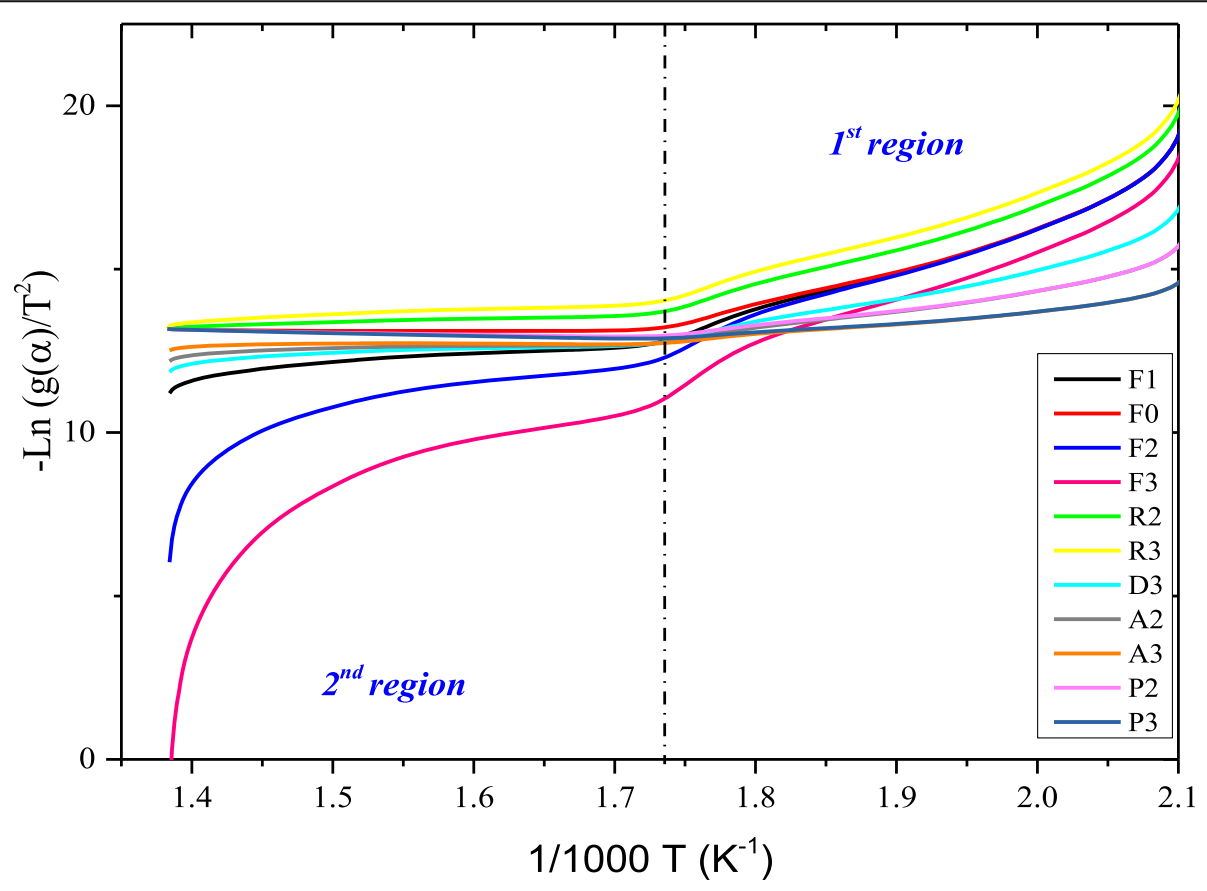

Fig. 9 Curves indicating the solid-state mechanisms of bulk aluminum oxide degradation under inert atmosphere 
Table 3 Thermal kinetic results for bulk aluminum oxide pyrolysis

\begin{tabular}{|c|c|c|c|c|c|c|}
\hline \multirow[t]{2}{*}{ MD } & \multicolumn{3}{|l|}{ 1st region } & \multicolumn{3}{|l|}{ 2nd region } \\
\hline & $\mathrm{Ea}\left(\mathrm{kJ} \cdot \mathrm{mol}^{-1}\right)$ & $\mathrm{R}^{2}$ & $\operatorname{Ln} A\left(\min ^{-1}\right)$ & $\mathrm{Ea}\left(\mathrm{kJ} \cdot \mathrm{mol}^{-1}\right)$ & $R^{2}$ & $\operatorname{Ln} A\left(\min ^{-1}\right)$ \\
\hline F1 & 122.537 & 0.95148 & -8.323 & 9.262 & 0.84556 & 12.832 \\
\hline Fo & 116.238 & 0.94047 & -6.845 & 0.259 & 0.00617 & 11.554 \\
\hline F2 & 126.387 & 0.97401 & -9.275 & 71.801 & 0.88681 & 1.649 \\
\hline F3 & 135.861 & 0.9674 & -12.151 & 121.250 & 0.89997 & -9.252 \\
\hline R2 & 118.969 & 0.94747 & -6.793 & 9.561 & 0.96141 & 13.728 \\
\hline R3 & 120.262 & 0.94866 & -6.691 & 14.454 & 0.94953 & 13.479 \\
\hline P3 & 33.097 & 0.91717 & 9.164 & -6.984 & 0.97796 & - \\
\hline D3 & 78.465 & 0.9505 & 0.470 & 12.347 & 0.9151 & 12.515 \\
\hline P2 & 53.789 & 0.93044 & 5.355 & -5.219 & 0.94073 & - \\
\hline A2 & 56.764 & 0.94564 & 4.686 & 7.154 & 0.837 & 13.051 \\
\hline A3 & 35.1 & 0.93365 & 8.740 & 1.373 & 0.29837 & 12.596 \\
\hline
\end{tabular}

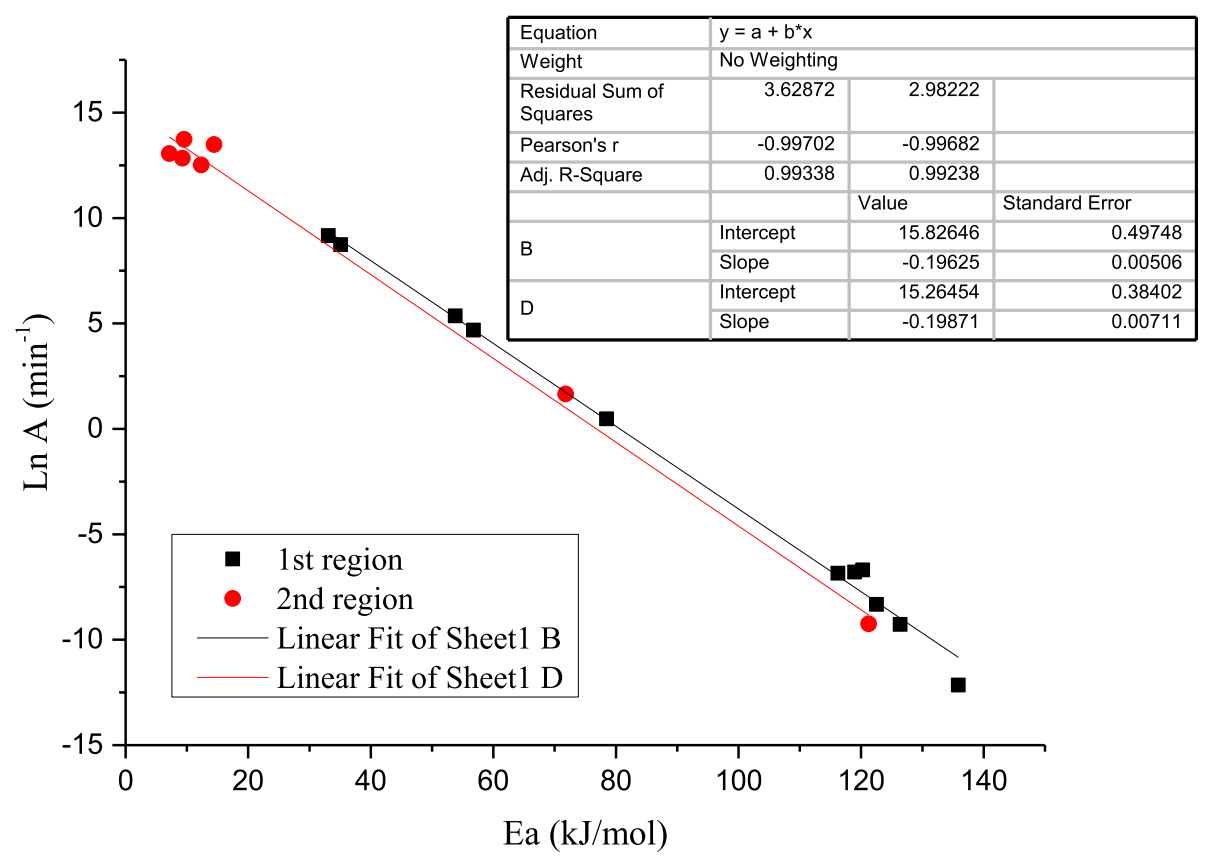

Fig. 10 Compensation effect $\operatorname{Ln} A=f\left(E_{a}\right)$ for first and second regions of thermal degradation 


\section{Abbreviations}

TGA: Thermogravimetric analysis; $f(a)$ : Represents the mode of degradation of the substance; $g(a)$ : Integral form of the function $f(a)$; A: Pre-exponential factor $\left[\mathrm{min}^{-1}\right]$; E: Apparent activation energy $\left[\mathrm{KJ}_{\mathrm{mol}} \mathrm{mo}^{-1}\right]$; $\mathrm{k}$ : Reaction rate constant $\left[\mathrm{min}^{-1}\right] ; m_{0}$ : Initial weight of the sample, $[\mathrm{mg}] ; m_{t}$ : Weight of the sample at the particular temperature $\mathrm{T}[\mathrm{mg}] ; m_{\infty}$ : Weight at the end of degradation step $[\mathrm{mg}] ; \beta$ : Heating rate $\left[{ }^{\circ} \mathrm{C} \cdot \mathrm{min}^{-1}\right] ; \mathrm{R}$ : Constante des gaz parfait $\left[\mathrm{J} . \mathrm{mol}^{-1} . \mathrm{K}^{-1}\right]$; T: Absolute temperature $[\mathrm{K}] ; \mathrm{T}_{0}$ : Initial température $[\mathrm{K}]$; t: Time [min]; n: Reaction order; $a$ : Conversion rate

\section{Acknowledgments}

This work was completed in the ELTE Institutional Excellence Program (17833/2018/FEKUTSRAT) supported by the Hungarian Ministry of Human Capacities. Open access funding provided by Eötvös Loránd Eötvös University (ELTE).

\section{Authors' contributions}

The authors read and approved the final manuscript.

\section{Funding}

Not applicable.

\section{Availability of data and materials}

The authors declare that the availability of data and materials.

\section{Declarations}

\section{Competing interests}

The authors declare that they have no competing interests.

\section{Author details}

'Doctoral School of Environmental Sciences, Eötvös Loránd University, Budapest $\mathrm{H}-1117$, Hungary. ${ }^{2}$ Department of Chemistry, Hafr Al-Batin University, Hafar Al Batin, Saudi Arabia. ${ }^{3}$ Institute of Chemistry, Eötvös Loránd University, Budapest $\mathrm{H}-1117$, Hungary.

\section{Received: 27 January 2021 Accepted: 25 October 2021}

\section{Published online: 02 December 2021}

\section{References}

1. Bagheri Khatibani, A., Rozati, S.M.: Synthesis and characterization of amorphous aluminum oxide thin films prepared by spray pyrolysis: effects of substrate temperature. J. Non-Cryst. Solids. 363, 121-133 (2013). https:// doi.org/10.1016/j.jnoncrysol.2012.12.013

2. Isac, L., Duta, A., Purghel, E., Chitanu, G.C., Mitrea, S., Pelin, I.: Tailoring alumina thin film properties using hydrophilic/hydrophobic copolymer additives. Phys. Status Solidi Appl. Mater. Sci. 205(10), 2413-2416 (2008). https://doi.org/10.1002/pssa.200779429

3. Smet, P.F., Lauwaert, J., Avci, N., Poelman, D., Vrielinck, H.: Optical and structural properties of aluminium oxide thin films prepared by a nonaqueous sol-gel technique. J. Sol-Gel Sci. Technol. 59(2), 327-333 (2011). https://doi.org/10.1007/s10971-011-2505-9

4. X. Nie, E.I. Meletis, J.C. Jiang, A. Leyland, A.L. Yerokhin, A. Matthews, Abrasive wear/corrosion properties and TEM analysis of Al2O3 coatings fabricated using plasma electrolysis, Surf. Coatings Technol. 149 (2002) 245-251. https://doi.org/10.1016/S0257-8972(01)01453-0, 2-3

5. Wang, Y., Lim, S., Luo, J.L., Xu, Z.H.: Tribological and corrosion behaviors of Al203/polymer nanocomposite coatings. Wear. 260(9-10), 976-983 (2006). https://doi.org/10.1016/j.wear.2005.06.013

6. Boström, T., Westin, G., Wäckelgård, E:: Optimization of a solution-chemically derived solar absorbing spectrally selective surface. Sol. Energy Mater. Sol. Cells. 91(1), 38-43 (2007). https://doi.org/10.1016/j.solmat.2006.07.002

7. Cui, J., Kast, M.G., Hammann, B.A., Afriyie, Y., Woods, K.N., Plassmeyer, P.N. Perkins, C.K., Ma, Z.L., Keszler, D.A., Page, C.J., Boettcher, S.W., Hayes, S.E.: Aluminum oxide thin films from aqueous solutions: insights from solid-state NMR and dielectric response. Chem. Mater. 30(21), 7456-7463 (2018). https://doi.org/10.1021/acs.chemmater.7b05078

8. Yu, B.-G., Shin, C.H., Lee, H.C., Cha, S.Y., Kwak, D.-H., Lee, W.-J.: Fabrication and characterization of MFISFET using Al 203 insulating layer for nonvolatile memory. Integr. Ferroelectr. 34(1-4), 113-120 (2007). https://doi. org/10.1080/10584580108012880
9. J. Gottmann, E.W. Kreutz, Pulsed laser deposition of alumina and zirconia thin films on polymers and glass as optical and protective coatings, Surf. Coatings Technol. 116-119 (1999) 1189-1194. https://doi.org/10.1016/S02 57-8972(99)00191-7

10. Vitanov, P., Harizanova, A., Ivanova, T., Dimitrova, T.: Chemical deposition of Al2O3 thin films on Si substrates. Thin Solid Films. 517(23), 6327-6330 (2009). https://doi.org/10.1016/j.tsf.2009.02.085

11. Płóciennik, P., Guichaoua, D., Korcala, A., Zawadzka, A.: Studies of aluminum oxide thin films deposited by laser ablation technique. Opt. Mater. (Amst). 56, 49-57 (2016). https://doi.org/10.1016/j.optmat.2016.01.060

12. Yang, H., Liu, M., Ouyang, J.: Novel synthesis and characterization of nanosized Y-Al2O3 from kaolin. Appl. Clay Sci. 47(3-4), 438-443 (2010). https://doi.org/10.1016/j.clay.2009.12.021

13. Balakrishnan, G., Kuppusami, P., Sundari, S.T., Thirumurugesan, R., Ganesan, V. Mohandas, E., Sastikumar, D.: Structural and optical properties of $y$-alumina thin films prepared by pulsed laser deposition. Thin Solid Films. 518(14), 3898-3902 (2010). https://doi.org/10.1016/j.tsf.2009.12.001

14. Blittersdorf, S., Bahlawane, N., Kohse-Höinghaus, K., Atakan, B., Müller, J.: CVD of $\mathrm{Al} 2 \mathrm{O} 3$ thin films using aluminum tri-isopropoxide. Chem. Vap. Depos. 9(4), 194-198 (2003). https://doi.org/10.1002/cvde.200306248

15. Hwang, Y., Heo, K., Chang, C.H., Joo, M.K., Ree, M.: Synchrotron X-ray reflectivity study of high dielectric constant alumina thin films prepared by atomic layer deposition. Thin Solid Films. 510(1-2), 159-163 (2006). https:// doi.org/10.1016/j.tsf.2005.12.162

16. Cibert, C., Hidalgo, H., Champeaux, C., Tristant, P., Tixier, C., Desmaison, J., Catherinot, A.: Properties of aluminum oxide thin films deposited by pulsed laser deposition and plasma enhanced chemical vapor deposition. Thin Solid Films. 516(6), 1290-1296 (2008). https://doi.org/10.1016/j.tsf.2007.05.064

17. Boidin, R., Halenkovič, T., Nazabal, V., Beneš, L., Němec, P.: Pulsed laser deposited alumina thin films. Ceram. Int. 42(1), 1177-1182 (2016). https:// doi.org/10.1016/j.ceramint.2015.09.048

18. Dhonge, B.P., Mathews, T., Sundari, S.T., Thinaharan, C., Kamruddin, M., Dash, S., Tyagi, A.K.: Spray pyrolytic deposition of transparent aluminum oxide (Al 203) films. Appl. Surf. Sci. 258(3), 1091-1096 (2011). https://doi.org/10.1016/ j.apsusc.2011.09.040

19. Adamopoulos, G., Thomas, S., Bradley, D.D.C., McLachlan, M.A., Anthopoulos, T.D.: Low-voltage $\mathrm{ZnO}$ thin-film transistors based on $\mathrm{Y}_{2} \mathrm{O} 3$ and $\mathrm{Al} 2 \mathrm{O} 3$ high- $\mathrm{k}$ dielectrics deposited by spray pyrolysis in air. Appl. Phys. Lett 98(12), 2009-2012 (2011). https://doi.org/10.1063/1.3568893

20. Ienei, E., Isac, L., Duță, A.: Synthesis of alumina thin films by spray pyrolysis. Rev. Roum. Chim. 55, 161-165 (2010)

21. Khanna, A., Bhat, D.G., Harris, A., Beake, B.D.: Structure-property correlations in aluminum oxide thin films grown by reactive $A C$ magnetron sputtering Surf. Coatings Technol. 201(3-4), 1109-1116 (2006). https://doi.org/10.1016/j. surfcoat.2006.01.033

22. Gianneta, V., Nassiopoulou, A.G., Krontiras, C.A., Georga, S.N.: Porous anodic alumina thin films on Si: Interface characterization. Phys. Status Solidi Curr. Top. Solid State Phys. 5(12), 3686-3689 (2008). https://doi.org/10.1002/pssc.2 00780160

23. Wang, T., Pu, J., Bo, C., Jian, L.: Sol-gel prepared Al2O3 coatings for the application as tritium permeation barrier. Fusion Eng. Des. 85(7-9), 10681072 (2010). https://doi.org/10.1016/j.fusengdes.2010.01.021

24. Vanbesien, K., De Visschere, P., Smet, P.F., Poelman, D.: Electrical properties of Al2O3 films for TFEL-devices made with sol-gel technology. Thin Solid Films. 514(1-2), 323-328 (2006). https://doi.org/1 0.1016/j.tsf.2006.02.034

25. Moubah, R., Colis, S., Leuvrey, C., Schmerber, G., Drillon, M., Dinia, A.: Synthesis and characterization of $\mathrm{Ca} 3 \mathrm{CO} 4 \mathrm{O} 9$ thin films prepared by sol-gel spin-coating technique on Al2O 3(001). Thin Solid Films. 518(16), 4546-4548 (2010). https://doi.org/10.1016/j.tsf.2009.12.027

26. Ferrari, V.C., Dupim, I.S., Sousa, V., Souza, F.L.: Photoactive multilayer WO3 electrode synthesized via dip-coating. Ceram. Int. 44(18), 22983-22990 (2018). https://doi.org/10.1016/j.ceramint.2018.09.097

27. Farid, R., Rajan, K., Sarkar, D.K.: Enhanced corrosion protection of aluminum by ultrasonically dip coated sodium silicate thin films. Surf. Coatings Technol. 374, 355-361 (2019). https://doi.org/10.1016/j.surfcoat.2019.05.082

28. Zelcer, A., Saleh Medina, L.M., Hoijemberg, P.A., Fuertes, M.C.: Optical quality mesoporous alumina thin films. Microporous Mesoporous Mater. 287, $211-$ 219 (2019). https://doi.org/10.1016/j.micromeso.2019.05.006

29. Redfern JP. "Thermogravimetric Analysis," Analyst, vol. 88, no. 1053, pp. 906 924, 1963. 
30. Bouzbib, M., Pogonyi, A., Kolonits, T., Vida, Á., Dankházi, Z., Sinkó, K.: Sol - gel alumina coating on quartz substrate for environmental protection. J. Sol-Gel Sci. Technol. 93(2), 262-272 (2020). https://doi.org/10.1007/s10971-019-051 93-y

31. Chandradass, J., Bae, D.S.: Synthesis and characterization of alumina nanoparticles by Igepal CO-520 stabilized reverse micelle and sol-gel processing. Mater. Manuf. Process. 23(5), 494-498 (2008). https://doi.org/10.1 080/10426910802104211

32. Criado J.M, Malek J., Ortega A., "APPLICABILITY OF THE MASTER PLOTS IN KINETIC ANALYSIS," Thermochim. Acta, vol. 147, no. 2, pp. 377-385, 1989.

33. Villanueva M., "Thermogravimetric study of the decomposition process of the system," Polymer., vol. 41, no. 12, pp. 4635-4641, 2000.

34. Dickinson, C.F., Heal, G.R.: Thermochimica Acta A review of the ICTAC Kinetics Project, 2000 Part 1. Isothermal Results. 494(1-2), 1-14 (2009). https://doi.org/10.1016/j.tca.2009.05.003

35. Bustamante, L., Rogaume, T., Guillaume, E: Analysis of Principal Gas Products During Combustion of Polyether Polyurethane Foam at Different Irradiance Levels. 933-940 (2009). https://doi.org/10.1016/j.firesaf.2009.05.003f

36. Avrami, M.: Kinetics of Phase Change. I Gen. Theory. 1103, (1939). https:// doi.org/10.1063/1.1750380

37. Liu, F., Lai, Y., Liu, J., Wang, B., Kuang, S., Zhang, Z., Li, J., Liu, Y. Characterization of chemical bath deposited CdS thin films at different deposition temperature. J. Alloys Compd. 493(1-2), 305-308 (2010). https:// doi.org/10.1016/j.jallcom.2009.12.088

38. Van Lare, C., Lenzmann, F., Verschuuren, M.A., Polman, A.: Dielectric scattering patterns for efficient light trapping in thin-film solar cells. Nano Lett. 15(8), 4846-4852 (2015). https://doi.org/10.1021/nl5045583

39. $\mathrm{Hu}, \mathrm{B} ., \mathrm{Jia}, \mathrm{E} ., \mathrm{Du}, \mathrm{B}$. Y Yin, Y.: A new sol-gel route to prepare dense Al2O3 thin films. Ceram. Int. 42(15), 16867-16871 (2016). https://doi.org/10.1016/j.cera mint.2016.07.181

40. Barrie, P.J.: The mathematical origins of the kinetic compensation effect: 1. the effect of random experimental errors. Phys. Chem. 14, 318-326 (2012). https://doi.org/10.1039/c1cp22666e

\section{Publisher's Note}

Springer Nature remains neutral with regard to jurisdictional claims in published maps and institutional affiliations.

\section{Submit your manuscript to a SpringerOpen ${ }^{\circ}$ journal and benefit from:}

- Convenient online submission

- Rigorous peer review

- Open access: articles freely available online

High visibility within the field

- Retaining the copyright to your article

Submit your next manuscript at $\boldsymbol{\nabla}$ springeropen.com 